\title{
IMPACTOS DA COVID-19 NO MERCADO: RECUPERAÇÃO JUDICIAL E NOVOS DESAFIOS
}

\author{
José Cláudio Junqueira Ribeiro ${ }^{1}$ \\ Alex Floriano Neto ${ }^{2}$
}

\begin{abstract}
Resumo: O artigo tem como finalidade enfrentar o seguinte problema: quais mecanismos poderão ser emprestados ao empresário, na busca pela superação da crise econômicofinanceira decorrente da COVID-19 e os desafios que o empresário enfrentará? Para tanto, o artigo aborda os aspectos objetivos da COVID-19 e seu reconhecimento como Pandemia, bem como a declaração da situação nacional como de Emergência em Saúde Pública de Importância Nacional (ESPIN) e como tal fato impacta no mercado, nos negócios e no exercício das atividades dos empresários, deixando-os numa situação de apuros econômico-financeiros. A metodologia utilizada foi do método dedutivo de pesquisa e raciocínio, com análise de normas e literatura acerca no tema. Acredita-se que que os objetivos foram alcançados e que a recuperação judicial pode ser objeto de análise econômica, neste momento, com vistas a buscar maior adequação e eficiência do instituto. Concluiu-se, ao final, que a recuperação judicial se mostra uma importante ferramenta para o empresário, a despeito dos desafios propostos.
\end{abstract}

Palavras-chave: COVID-19; impactos; mercado; empresário; recuperação judicial; desafios.

\section{MARKET IMPACTS OF COVID-19: JUDICIAL RECOVERY AND NEW CHALLENGES}

\begin{abstract}
The article aims to tackle the following problem: what mechanisms can be lent to the entrepreneur, in the quest to overcome the economic and financial crisis resulting from COVID-19 and the challenges that the entrepreneur will face? To this end, the article addresses the objective aspects of COVID-19 and its recognition as a Pandemic, as well as the declaration of the national situation as of Public Health Emergency of National Importance (ESPIN) and how this fact impacts the market, business and the exercise of the activities of entrepreneurs, leaving them in a situation of economic and financial difficulties. The methodology used was the deductive method of research and reasoning, with analysis of standards and literature on the subject. It is believed that the objectives have been achieved and that judicial recovery can be the object of economic analysis, at this moment, with a view to seeking greater adequacy and efficiency of the institute. It was concluded, in the end, that the judicial recovery proves to be an important tool for the entrepreneur, despite the proposed challenges.
\end{abstract}

\footnotetext{
${ }^{1}$ Doutor em Saneamento, Meio Ambiente e Recursos Hídricos pela UFMG. Professor de Gestão Ambiental na graduação na EMGE e no Programa de Pós-Graduação da Escola Superior Dom Helder Câmara.

2 Doutorando e Mestre em Direito. Professor da Escola Superior Dom Helder Câmara. Advogado e professor.
} 
Keywords: COVID-19; impacts; market; businessman; judicial recovery; challenges. 


\section{INTRODUÇÃO}

O presente artigo abordará o surgimento da COVID-19 no Brasil e seu tratamento como Pandemia e a declaração da situação nacional como de Emergência em Saúde Pública de Importância Nacional (ESPIN) e como tal fato apresenta impactos relevantes para o mercado, os negócios e o exercício das atividades econômicas pelos empresários, deixando-os numa situação de apuros econômico-financeiros.

Nesse cenário, o artigo tratará das controvérsias acerca da suspensão de determinadas atividades econômicas no município de Belo Horizonte/MG e da manutenção daquelas denominadas essenciais, buscando compreender o critério utilizado pelo Poder Público em tal definição.

Além disso, será realizada análise de normas pertinentes aos princípios que se aplicam às situações criadas com a suspensão de determinadas atividades e o impacto para aqueles empresários que tiveram suas atividades suspensas, bem como para aqueles que, mesmo mantendo sua atuação, não conseguiram gerar novos negócios e produzir riquezas.

Diante desse contexto, há que se analisar as ferramentas existentes e aquelas necessárias para o ajuste no exercício das atividades empresariais, o que pode ser verificado tanto pelas medidas de enfrentamento da crise, como pela mais adequada compreensão do instituto da recuperação judicial e sua pertinência no contexto da crise decorrente dessa Pandemia.

Assim, o tema central do artigo é a análise acerca dos efeitos decorrentes da Pandemia da COVID-19 e os novos desafios para utilização da recuperação judicial como importante ferramenta para soerguimento diante das novas imposições do mercado atual.

A relevância do tema se justifica na medida em que o mercado se encontra em situação delicada e carece de direcionamento para que os empresários possam enxergar possíveis e novos caminhos para manutenção de seus negócios. Para tanto, o artigo adotará como referencial teórico a Teoria Jurídica da Empresa e se desenvolverá pelo método dedutivo de pesquisa e raciocínio, com análise de normas e doutrina especializada no tema, buscando a compreensão e enfrentamento do problema proposto. 


\title{
1. CRONOLOGIA DA COVID-19: PANDEMIA E EMERGÊNCIA EM SAÚDE PÚBLICA DE IMPORTÂNCIA NACIONAL (ESPIN)
}

Esse artigo não tem o objetivo de examinar os aspectos relativos a saneamento, quando se propõe a trazer à baila questões objetivas da COVID-19. Em verdade, o que se pretende é contextualizar a atual e mais grave crise econômico-financeira pela qual os empresários brasileiros foram submetidos, em razão de um vírus letal, que paralisou todo o globo.

A COVID-19 inicia sua saga no país chinês, o qual avisou para o mundo acerca da existência do vírus no final de dezembro de 2019, quando a Organização Mundial de Saúde - OMS foi comunicada dos vários casos identificados naquele país, que conta atualmente com mais de 11.000 .000 (onze milhões) de habitantes.

Ainda no início da descoberta do vírus e da doença por ele causada, a China apresentou infecção generalizada, o que causou a morte de milhares de chineses, além de aumentar a preocupação mundial, em razão do avanço do vírus e da doença para outros 05 (cinco) continentes.

Na China, a primeira morte foi confirmada em 11 de janeiro de 2020. Já no Brasil, o primeiro caso foi confirmado em 26 de fevereiro de 2020 e a primeira morte registrada em 17 de março do mesmo ano. Percebeu-se, então, que o vírus tinha capacidade de avanço e disseminação em massa, o que obrigou a OMS a reconhecer e decretar emergência de saúde pública de interesse internacional.

A pressão mundial não deixou outra alternativa para a OMS, como registra a matéria da $\mathrm{BBC}^{3}$ datada de 31 de janeiro de 2020:

\begin{abstract}
A OMS tradicionalmente reluta em declarar emergências internacionais a não ser que seja absolutamente necessário, explica a correspondente da BBC em Genebra, Imogen Foulkes. Mas sucumbiu, diante do aumento expressivo de casos (que aumentaram de 500 para quase 8 mil em menos de uma semana) e de mortes (que passaram de 17 para 170).
\end{abstract}

Considerando que a situação de Pandemia alastrou-se rapidamente e colocou a situação de saúde no Brasil em estado de alerta, o Ministério da Saúde também se viu pressionado pela população e governantes dos entes federados a reconhecer e decretar

\footnotetext{
${ }^{3}$ Matéria extraída do sítio eletrônico: https://www.bbc.com/portuguese/internacional-51198297.
} 
emergência de saúde pública de importância nacional (ESPIN), por meio da Portaria n. 188 , em 3 de fevereiro de $2020^{4}$ :

Art. $1^{\circ}$ Declarar Emergência em Saúde Pública de Importância Nacional conforme Decreto $\mathrm{n}^{\circ}$ 7.616, de 17 de novembro de 2011;

Art. $2^{\circ}$ Estabelecer o Centro de Operações de Emergências em Saúde Pública $(\mathrm{COE}-\mathrm{nCoV})$ como mecanismo nacional da gestão coordenada da resposta à emergência no âmbito nacional.

Tecidas breves considerações acerca da cronologia da Pandemia que assola o país, no tópico seguinte serão demonstrados os danos efeitos experimentados em razão dos impactos que a COVID-19 apresenta em cenário mundial, notadamente como se estabeleceu no contexto brasileiro.

\section{EFEITOS DECORRENTES DA PANDEMIA NO MERCADO E NOS NEGÓCIOS.}

Registra-se, brevemente, por se tratar de fato notório, que a pandemia paralisou várias atividades, especialmente diante do temor inicial, ocasião na qual ainda não haviam muitas informações acerca do vírus, formas de contágio e de prevenção seguras para a população.

Diante disso, os entes federados passaram a administrar o controle das atividades conforme competência constitucional e identificação da necessidade de atuação mais rigorosa e restritiva, como forma de conter o avanço do vírus e preservar a saúde das pessoas.

Nesse contexto, tanto o governo federal como outros entes federados buscaram atuações pontuais e formas estratégicas para gestão pública, por meio da declaração de estado de calamidade pública, iniciando-se pelo decreto legislativo n. 06, editado pela União Federal, em 20 de março de 2020, que diz o seguinte:

\footnotetext{
Art. $1^{\circ}$ Fica reconhecida, exclusivamente para os fins do art. 65 da Lei Complementar $\mathrm{n}^{\mathbf{0}} 101$, de 4 de maio de 2000, notadamente para as dispensas do atingimento dos resultados fiscais previstos no art. $2^{\circ}$ da Lei ${ }^{\circ} 13.898$, de 11 de novembro de 2019, e da limitação de empenho de que trata o art. $9^{\circ}$ da Lei Complementar $\mathrm{n}^{\circ} 101$, de 4 de maio de 2000, a ocorrência do estado de calamidade pública, com efeitos até 31 de dezembro de 2020, nos termos da solicitação do Presidente da República encaminhada por meio da Mensagem $n^{\circ} 93$, de 18 de março de 2020.
}

\footnotetext{
${ }^{4}$ http://www.in.gov.br/en/web/dou/-/portaria-n-188-de-3-de-fevereiro-de-2020-241408388
} 
Assim, ficou reconhecida a situação de estado de calamidade pública nacional, em razão da COVID-19 até 31 de dezembro de 2020. Diante disso, outros entes federados também estabeleceram estratégias semelhantes e editaram outras normas com a mesma finalidade, senão veja-se como exemplo o Estado de Minas Gerais, que por meio do decreto n. 47.891 , de 20 de março de 2020 decretou estado de calamidade até a mesma data:

Art. $1^{\circ}$ Fica decretado, para fins de aplicação do art. 65 da Lei complementar Federal $n^{\circ} 101$, de 4 de maio de 2000, estado de calamidade pública no âmbito de todo o território do Estado, com efeitos até o dia 31 de dezembro de 2020, em razão dos impactos socioeconômicos e financeiros decorrentes da pandemia causada pelo agente coronavírus (COVID-19).

A questão polêmica que se coloca após o reconhecimento do estado de calamidade pública nacional e estadual (no caso de Minas Gerais) é a suspensão de determinadas atividades, por meio de suspensão dos alvarás de funcionamento em alguns municípios brasileiros.

A título de exemplificação, tem-se o município de Belo Horizonte/MG, que por meio de seu Prefeito Municipal, editou o decreto n. 17.304, de 18 de março de 2020, determinando a suspensão dos alvarás de funcionamento para diversas atividades, mantendo-se aquelas compreendidas como essenciais.

Nota-se que o decreto permitiu a continuidade do exercício de determinadas atividades, consideradas essenciais, relegando à paralisação as demais, mesmo sem explicação do reputado caráter de essencialidade, o que, inicialmente, coloca em cheque os princípios constitucionais da isonomia e da livre iniciativa, previstos nos artigos $5^{\circ}$ caput e inciso XIII, 170 caput e parágrafo único, todos da Carta Política ${ }^{5}$.

Diante da polêmica e o desentendimento nacional para estabelecimento da essencialidade de determinadas atividades, a situação tornou-se ainda mais nebulosa

\footnotetext{
${ }^{5}$ Art. $5^{\circ}$ Todos são iguais perante a lei, sem distinção de qualquer natureza, garantindo-se aos brasileiros e aos estrangeiros residentes no País a inviolabilidade do direito à vida, à liberdade, à igualdade, à segurança e à propriedade, nos termos seguintes:

$[\ldots]$

XIII - é livre o exercício de qualquer trabalho, ofício ou profissão, atendidas as qualificações profissionais que a lei estabelecer;

Art. 170. Art. 170. A ordem econômica, fundada na valorização do trabalho humano e na livre iniciativa, tem por fim assegurar a todos existência digna, conforme os ditames da justiça social, observados os seguintes princípios:

$[\ldots]$

Parágrafo único. É assegurado a todos o livre exercício de qualquer atividade econômica, independentemente de autorização de órgãos públicos, salvo nos casos previstos em lei.
} 
com a publicação do decreto n. 10.282, de 20 de março de 2020, pela União Federal, aumentando o número de atividades essenciais, no art. $3^{\circ}, \S 1^{\circ}$, que diz:

Art. $3^{\circ}[\ldots]$

$\S 1^{\circ}$ São serviços públicos e atividades essenciais aqueles indispensáveis ao atendimento das necessidades inadiáveis da comunidade, assim considerados aqueles que, se não atendidos, colocam em perigo a sobrevivência, a saúde ou a segurança da população, tais como:

Não obstante, a suspensão de algumas atividades agravou o estado de crise daqueles empreendimentos que já se encontram em situação delicada e passaram a amargar estado de apuros econômicos, com consequente insolvência de vários empresários, que não suportaram o custo da estrutura sem a geração de novos negócios e, com isso, receitas necessárias à manutenção de suas atividades.

Especialistas atribuem à ausência de políticas macroeconômicas compensatórias para enfrentamento dos efeitos decorrentes da COVID-19 o agravamento da crise e dos impactos no mercado que, como se verifica, tem aniquilado diariamente vários negócios.

Nessa linha, FERREIRA JÚNIOR e SANTA RITA (2020, p. 466):

O mapeamento dos canais de propagação do vírus e seus reflexos dinâmicos sobre o sistema econômico, em um exercício sem políticas macroeconômicas compensatórias, mostra, no primeiro momento, os impactos econômicos da Covid-19 na estrutura da economia e as graves consequências econômicas e sociais da falta de tempestividade das políticas públicas.

Deveras, a pandemia vem gerando prejuízos a todos, particulares e governos, sendo igualmente livre de dúvida que os empresários não deram causa a tal evento desastroso, mas estão padecendo com a ausência de políticas econômicas de enfrentamento da crise capazes de lhes permitir a manutenção de suas atividades.

Com relação à crise, pode-se destacar como motivos decorrentes do despreparo da economia a ausência de novos negócios, impossibilidade de manutenção dos custos com estrutura e pessoal, incertezas e insegurança de investidores e consumidores também afetados pelos efeitos econômicos da Pandemia.

Diante da situação de crise e após pesquisas sobre dados obtidos junto a institutos responsáveis pelo estudo sobre os efeitos decorrentes da COVID-19 para os negócios no Brasil, Bernardes, Silva e Lima (p. 44, 2020) ponderaram o seguinte:

Diante disto, as organizações precisam se preparar para um período de recessão pós Covid19 e de condições de negócios adversas. Para a maior parte das organizações, a receita perdida nesse período pode representar uma perda permanente e exercer pressões em sua liquidez e nas fontes de capital de giro. 
No mesmo sentido, percebe-se o posicionamento extraído de matéria junto ao sítio eletrônico da FIOCRUZ (2020) ${ }^{6}$ :

A pandemia da Covid-19, causada pelo vírus SARS-CoV-2 ou Novo Coronavírus, vem produzindo repercussões não apenas de ordem biomédica e epidemiológica em escala global, mas também repercussões e impactos sociais, econômicos, políticos, culturais e históricos sem precedentes na história recente das epidemias.

A estimativa de infectados e mortos concorre diretamente com o impacto sobre os sistemas de saúde, com a exposição de populações e grupos vulneráveis, a sustentação econômica do sistema financeiro e da população, a saúde mental das pessoas em tempos de confinamento e temor pelo risco de adoecimento e morte, acesso a bens essenciais como alimentação, medicamentos, transporte, entre outros.

Percebe-se, pois, que a Pandemia de efeitos catastróficos não só aniquilou vários empreendimentos, como também continua assombrando aqueles que tiveram seus negócios afetados e estão diuturnamente reinventando sua atuação, com vistas muitas vezes a manter a fonte produtora de receitas, até que alguma política econômica ou medidas agressivas de enfrentamento sejam efetivamente adotadas no país.

Registra-se que o governo federal editou medidas provisórias, com objetivo de instituir estratégias mínimas para enfrentamento dos impactos econômicos oriundos da COVID-19, estabelecendo possibilidade de suspensão de contratos de trabalho, redução de carga horária e diferimento de pagamentos de contribuições e tributos. Um exemplo é a MP n. 927/2020, que trouxe um novo padrão de atuação com o teletrabalho.

A medida provisória em questão não foi convertida em lei no prazo estabelecido pela Constituição Federal de 1988, tendo perdido sua validade em 19 de julho de 2020. Assim, as situações jurídicas criadas durante a vigência da MP serão regidas pelas normas constantes da própria medida provisória acaso não seja editado o decreto legislativo pelo Congresso Nacional em até 60 (sessenta) dias, contados da perda de sua eficácia.

Diante desse cenário, revela-se importante a reflexão acerca da compreensão e possível utilização do instituto da recuperação judicial como ferramenta de enfrentamento dos efeitos da Pandemia e na busca pela superação do estado de crise econômicofinanceira de empresários e de outros empreendedores que exercem atividades próprias de empresários.

No tópico seguinte serão demonstrados seus principais aspectos, para que seja possível, após sua contextualização, verificar a conveniência e oportunidade para

\footnotetext{
${ }^{6}$ https://portal.fiocruz.br/impactos-sociais-economicos-culturais-e-politicos-da-pandemia
} 
implementação da medida e verificação dos atuais desafios, haja vista o esvaziamento econômico, patrimonial e financeiro que assola grande parte dos empresários e sociedades empresárias do país.

\section{ASPECTOS OBJETIVOS DA RECUPERAÇÃO JUDICIAL}

A situação econômica do país reclama a existência de normas que permitam a reorganização e novos caminhos a serem emprestados aos empresários que se encontrem em situação de crise, para que possam gerar negócios, manter a fonte produtora de riquezas, o emprego de seus colaboradores e cumprir suas obrigações, além de sua função social.

Inicialmente, cumpre registrar que a lei 11.101/05 é detinada a empresários e sociedades empresárias, como se vê logo em seu artigo inaugural: "Art. $1^{o}$ Esta Lei disciplina a recuperação judicial, a recuperação extrajudicial e a falência do empresário e da sociedade empresária, doravante referidos simplesmente como devedor."

Dessa forma, importante esclarecer quem é considerado juridicamente empresário, para fins de se identificar aqueles que poderão fazer parte de processos recuperatórios ou falimentares. Tal explicação consta do Código Civil brasileiro, no artigo 966: “Art. 966. Considera-se empresário quem exerce profissionalmente atividade econômica organizada para a produção ou a circulação de bens ou de serviços."

Assim, empresário exercerá atividade visando lucro e assumindo risco. Mas, a despeito de o empreendimento apresentar seus riscos naturais, a economia deve ser um fator de análise, acompanhamento e condução por meio de políticas econômicas fortes e capazes de permitir a realização das atividades e a circulação de riquezas.

Assim, cabe ao Poder Público determinar instrumentos capazes de ajudar o empresário a se manter no mercado, na hipótese de sua atividade ser viável. Isso porque o empresário que demonstra ter viabilidade em sua atuação deve ser preservado e a ele ser permitida oportunidade de soerguimento, na hipótese de desequilíbrio de suas finanças, especialmente em situação como a Pandemia causada pela COVID-19. Nesse sentido, LISBOA (p. 41, 2005):

Dentro desse contexto, o marco legal falimentar deve oferecer às empresas e a seus credores (fornecedores, trabalhadores e instituições financeiras) condições para buscar uma solução que gere o melhor resultado possível para todas as partes envolvidas, seja ela (i) a recuperação da empresa, e consequentemente do seu negócio, (ii) a preservação do negócio sob o 
comando de um novo controlador (falência do antigo devedor) ou mesmo (iii) a extinção do negócio, com a realização dos ativos individualmente. (...) Acontece que a assimetria de informação no mercado é muito grande, e os credores não conseguem mensurar de forma segura o valor presente de seus fluxos futuros e a real viabilidade econômica de um negócio. Assim, a legislação falimentar deve ter a flexibilidade necessária e os mecanismos de transparência condizentes para que devedor e credores cheguem a uma solução que seja a melhor possível para a sociedade: a continuidade da capacidade de geração de emprego e renda da empresa, seja sob o controle do próprio devedor ou de outros agentes mais eficientes.

A lei de falências deve, então, criar um ambiente formal de negociação e de cooperação, estimulando credores e devedores no sentido da solução mais eficiente, seja ela a tentativa de recuperação ou, se não for possível, a falência da empresa.

Importante destacar que a atual lei de falências e recuperação (lei 11.101/2005) tem perfil diferenciado, pois visa estabelecer um ponto de equilíbrio entre interesses de credores e devedor, com vistas à busca pela composição de interesses das partes na consolidação de medidas capazes de permitir ao devedor em crise uma oportunidade de soerguimento, desde que demonstre sua viabilidade. Dessa forma, o que se busca é estabelecer proteção ao mercado e não propriamente às partes.

Nessa medida, ao se permitir que o empresário reorganize suas atividades, ajuste suas finanças, mantenha postos de trabalho, pague tributos e cumpra com suas obrigações, o instituto da recuperação (judicial ou extrajudicial) se revela um relevante mecanismo para superação de crises e organização do próprio mercado.

Entretanto, como se demonstrará adiante, a recuperação de empresas deve ser concedida apenas ao empresário merecedor, ou seja, aquele que ainda apresenta condições de se manter no mercado sem gerar novos ônus. Acerca dessa viabilidade, FRANCO e SZTAJN (p. 214, 2008):

Essa lei introduz a possibilidade da recuperação (judicial e extrajudicial da empresa em crise) ao lado da falência. Para que qualquer das formas de recuperação possa ser concedida é necessário que a situação da empresa, embora difícil, não esteja irremediavelmente comprometida. Perante a inviabilidade econômica a solução é a falência, procurando-se, todavia, quando da liquidação, adota critérios que minimizem os efeitos negativos carreados pelo procedimento, de molde a facultar a pronta recuperação da empresa, declarada insolvente sem onerar, indevidamente, o eventual adquirente (v. art. 142, da LRE).

Destaca-se que a recuperação de empresas foi a inovação constante da atual legislação falimentar. Considerando o problema proposto, este artigo focará no instituto da recuperação judicial. Em relação a tal instrumento de superação de crise, sua criação 
foi firmada para oportunizar ao empresário em crise a preservação da empresa, ou seja, a possibilidade de continuidade/manutenção de suas atividades.

A recuperação judicial está prevista no artigo 47 da lei 11.101/2005:

Art. 47. A recuperação judicial tem por objetivo viabilizar a superação da situação de crise econômico-financeira do devedor, a fim de permitir a manutenção da fonte produtora, do emprego dos trabalhadores e dos interesses dos credores, promovendo, assim, a preservação da empresa, sua função social e o estímulo à atividade econômica.

Na sequência, o legislador estabeleceu requisitos objetivos mínimos para que o empresário em crise pudesse apresentar seu pedido de recuperação judicial, de forma que fica claro o objetivo do legislador em prestigiar o empresário regular e que já esteja em atuação no mercado, por algum tempo.

Certamente, ao iniciar uma atividade econômica, o empresário assume determinados riscos, inclusive possíveis situações de crise, as quais podem ser voluntárias ou involuntárias. No caso dos impactos econômicos advindos da COVID-19, materializase uma espécie e crise involuntária, causada por fatores alheios ao controle e desejo do empresário, que não consegue realizar negócios para alavancar suas atividades e pagar pontualmente suas despesas e dívidas, repercutindo em perda patrimonial

Daí, há casos nos quais o empresário apresenta viabilidade econômica, ou seja, tem condições de gerar negócios, manter empregos e cumprir sua função socialmente relevante na sociedade, precisando, pois, de oportunidade para se reorganizar e ajustar sua situação patrimonial, o que pode ser viabilizado pela utilização da recuperação judicial. Sobre tal possibilidade, BEZERRA FILHO (p. 123, 2008):

A recuperação judicial destina-se às empresas que estejam em situação de crise econômico-financeira, com possibilidade, porém, de superação; pois aquelas em tal estado, mas em crise de natureza insuperável, devem ter sua falência decretada, até para que não se tornem elemento de perturbação do bom andamento das relações econômicas do mercado. [...]

Por isso mesmo, a Lei, não por acaso, estabelece uma ordem de prioridade nas finalidades que diz perseguir, colocando como primeiro objetivo a "manutenção da fonte produtora", ou seja, a manutenção da atividade empresarial em sua plenitude tanto quanto possível, com o que haverá possibilidade de manter também o "emprego dos trabalhadores". Mantida a atividade empresarial e o trabalho dos empregados, será possível então satisfazer os "interesses dos credores". Esta é a ordem de prioridades que a Lei estabeleceu - o exame abrangente da Lei poderá indicar se o objetivo terá condições de ser alcançado.

[...] Deverá o juiz sempre ter em vista, como orientação principiológica, a prioridade que a lei estabeleceu para a "manutenção da fonte produtora", ou seja, recuperação da empresa. 
Lado outro, além dos requisitos exigidos pela lei (artigos 48 e 51) o empresário interessado deverá comprovar que tem viabilidade econômica e merece ser agraciado com a recuperação judicial, demonstrando que sua situação de crise é momentânea e passível de ser sanada, resolvida e afastada.

O empresário deverá elaborar um plano de recuperação (plano de ações, com apontamento das medidas capazes de permitir seu soerguimento) e submetê-lo à apreciação de seus credores, para que estes possam analisar os documentos apresentados, a fim de deliberarem para aprovação, modificação ou rejeição do plano apresentado.

Nesse caso, caberá ao empresário em crise demonstrar que sua situação financeira lhe permite gerar negócios, sendo suficiente, após a reorganização advinda com a recuperação, para cumprir suas obrigações cobrir o passivo, bem como para pagamento de seus credores.

Postos esses apontamentos objetivos relativos aos principais aspectos da recuperação judicial e sua análise como instrumento de superação de crise econômicofinanceira, serão abordados no próximo tópico algumas reflexões jurídicas e econômicas para fins de identificação da viabilidade ou não da utilização daquele instituto no contexto da Pandemia da COVID-19.

\section{A RECUPERAÇÃO JUDICIAL COMO INSTRUMENTO DE SUPERAÇÃO DA CRISE DECORRENTE DA COVID-19 E SEUS DESAFIOS}

Após algumas tentativas para suavizar a situação dos empreendedores que estão padecendo com a crise que se instalou no país, em razão do confinamento exigido para controle da propagação da COVID-19, as medidas do governo ainda se revelaram tímidas e não têm conseguido impedir a devastação causada pela Pandemia.

Diante disso, como se antecipou acima, a proposta seria a análise de possível utilização da recuperação judicial de empresas como ferramenta capaz de ajudar o empresário devastado pela crise decorrente da COVID-19, dar amplitude e condições à implementação da recuperação judicial ou extrajudicial, vez que, ao que se percebe, a legislação falimentar foi cunhada para atribuir prioridade e prestígio primeiramente a tais institutos.

Portanto, o manejo da recuperação judicial no momento adequado, com a reunião de requisitos que demonstrem estar o empresário em situação passível de contornar a crise 
pela qual esteja passando pode ser considerado como o remédio mais adequado para situações como as que decorrem dos impactos da Pandemia que assola este país.

Tal ponderação justifica-se na medida em que se analisam alguns princípios econômicos que norteiam a ordem econômica brasileira e possibilitam a identificação da oportunidade de organização de mercado com a manutenção do empresário viável e afastamento daquele que, infelizmente, não tem mais condições de gerar negócios e produzir riquezas.

Ao se permitir que o empresário viável mantenha seus negócios, está-se prestigiando a preservação da unidade produtiva, pois a estrutura empresarial permite que o sujeito empresário se configure como um fenômeno econômico-social capaz não apenas de realizar suas atividades, mas produzir e promover a circulação de riquezas, além de manter postos de trabalho e colaborar com o desenvolvimento nacional, exatamente na medida desejada pelo citado art. 47 da lei 11.101/2005.

Em tempos de pânico, mortandades, crises econômico-financeiras e agravamento da situação de apuros econômicos, considerando a ausência de medidas agressivas para ajudar os empreendedores do país, causando insegurança e um clima de incertezas futuras, dada a impossibilidade de se vislumbrar o real impacto pós-pandemia, a recuperação judicial pode ser exatamente a medida de equilíbrio entre os interesses dos credores e o desejo do devedor de cumprir suas obrigações e superar a crise.

Como mencionado no capítulo anterior, a recuperação judicial permite aos empresários que se encontrem em estado de vulnerabilidade e sem condições de cumprir suas obrigações a oportunidade de soerguimento, desde que apresentem elementos capazes de convencer seus credores de que realmente poderão gerar negócios e produzir riquezas após reorganização.

Da mesma forma, vários desafios serão encontrados, haja vista que se trata de procedimento formal, para o qual o legislador exigiu uma série de requisitos objetivos e exibição de comprovantes de situação de crise.

Ademais, o legislador exigiu a prova de regularidade do empresário, não sendo, pois, aplicável o instituto aos chamados "informais". Outro aspecto importante é a necessidade de se manter um controle fiscal e contábil fidedigno, pois dentre os documentos exigidos do empresário são os balanços relativos aos últimos exercícios financeiros. 
Logo, vale destacar que muitos empresários, ainda que padeçam pela crise da qual não tem qualquer parcela de culpa e tenham, em tese, condições de gerar negócios, pagar os credores e superar a situação momentânea de crise, àqueles não será dada a oportunidade de sanear o estado de crise por meio do procedimento recuperatório.

Isso porque a recuperação judicial é um procedimento estruturado, com vários atos formais e exigência de documentos capazes de permitir que os credores possam avaliar, com o mínimo de segurança, se há ou não espaço para conceder ao empresário devedor a oportunidade para superação da crise.

O legislador buscou, como já dito, estabelecer mecanismos capazes de criar um ponto de tensão entre os interesses tanto de credores quanto do próprio devedor, com objetivo maior de proteger o mercado e o próprio crédito, já que a sociedade na qual se insere o devedor em crise suportará os danos efeitos colaterais decorrentes da manutenção de um empresário inviável no mercado.

A recuperação judicial bem sucedida poderá ensejar na reorganização das atividades do empresário e, consequentemente, na realização de novas atividades, realização de negócios, produção e circulação de riquezas, colaborando para a retomada da economia e o desenvolvimento nacional, sendo este último, a propósito elencado na Carta Política como um dos objetivos fundamentais da República: “Art. $3^{\circ}$ Constituem objetivos fundamentais da República Federativa do Brasil: (...) II - garantir o desenvolvimento nacional;",

Além disso, tanto os fornecedores que concedem a oportunidade de soerguimento, quanto o próprio empresário recuperado poderão criar novos negócios e cumprir não apenas sua função social, mas adotar postura capaz de atingimento de sua responsabilidade social perante o mercado, fomentando ações voltadas à proteção da sociedade onde estejam inseridos.

De acordo com BARACHO e CECATO (2016, p. 122):

\begin{abstract}
A responsabilidade social da empresa pode ser entendida como o planejamento sistemático de ações e estratégias que possibilitam um diálogo constante entre a empresa, público e a sociedade. O planejamento deve se voltar ao desenvolvimento sustentável e prever condições ideais de trabalho, condução dos negócios com ética e transparência, preservação do meio ambiente, ao atendimento dos consumidores e ao caminho ao novo desenvolvimento tecnológico.
\end{abstract}

Outra reflexão que se mostra possível no estudo da recuperação judicial como instrumento na busca pelo enfrentamento e superação da crise econômica decorrente da 
Pandemia da COVID-19 é a aplicação da análise econômica do Direito para identificar os caminhos mais adequados, do ponto de vista econômico, que os empresários poderiam adotar e os meios a serem utilizados de forma a atribuir maior eficiência ao instrumento de superação de crise em estudo.

Nessa linha de raciocínio, analisar economicamente o instituto da recuperação judicial para enfrentar os efeitos da Pandemia poderá colaborar com sua maturação e permitir que o contexto no qual se aplica, qual seja, a economia possa direcionar novos contornos jurídicos capazes de lhe emprestar maior eficiência, especialmente em razão dos novos desafios e dinâmica do mercado devastado pela crise.

Assim, ainda que se revele um desafio, a análise transdisciplinar entre Direito e Economia, num momento em que normas jurídicas não tem sido suficientes para contornar situações experimentadas no mercado, o que tem relegado à insolvência empresários, que não conseguiram manter suas atividades após o confinamento exigido para enfrentar os efeitos da Pandemia.

Nessa linha, possivelmente novas e criativas alternativas poderão ser desenvolvidas como forma de se enfrentar os impactos econômicos decorrentes da COVID-19, permitindo soluções inteligentes na luta pela reorganização de atividades econômicas, bem como apresentando reflexões acerca dos caminhos necessários para buscar a composição dos interesses dos relevantes agentes que atuam no mercado e nele encontram-se padecendo, sem medidas econômicas eficazes para sua salvação.

\section{CONSIDERAÇÕES FINAIS}

O presente artigo analisou aspectos relativos à COVID-19 no Brasil, desde seu surgimento, reconhecimento como Pandemia e a declaração da situação nacional como de Emergência em Saúde Pública de Importância Nacional (ESPIN), bem como os impactos econômicos que dela foram deflagrados.

Abordaram-se, ainda, controvérsias acerca da suspensão de determinadas atividades econômicas no município de Belo Horizonte/MG e da manutenção daquelas denominadas essenciais, com as respectivas normas que estabeleceram a essencialidade pelo Poder Público.

Nessa linha, foram problematizados os impactos na esfera jurídica daqueles empresários que tiveram suas atividades suspensas e, por conta disso, não conseguiram 
gerar novos negócios, deixando de produzir riquezas suficientes para sua manutenção e que medidas econômicas foram adotadas pelo governo, para fomentar o desenvolvimento de atividades durante a Pandemia.

Além disso, analisaram-se as ferramentas existentes e as que, em tese, poderiam ser necessárias à continuidade das atividades empresariais, propondo-se reflexões acerca da recuperação judicial como medida de enfrentamento da crise imposta pela Pandemia, sua análise econômica e desafios para sua implementação nesse contexto da COVID-19.

Para mais adequada compreensão sobre a recuperação judicial, buscou-se traçar os principais e objetivos aspectos pertinentes ao instituto, estabelecendo recortes sobre legitimidade, requisitos e objetivos que o legislador propôs ao empresário devedor, para buscar seu soerguimento e cumprimento de suas obrigações, no cenário de crise, tal como esse suportado mundialmente pela propagação da COVID-19.

Acredita-se que os objetivos propostos foram alcançados, na medida em que se o empresário implementar um instrumento capaz de possibilitar seu soerguimento, tal como a recuperação de empresas, as chances de superação da situação da crise econômicofinanceira aumentarão, o que possibilitará a continuidade de seus negócios, preservando a empresa.

Além disso, ao empregar esse meio alternativo para a superação da crise, o empresário permitirá a construção dos caminhos para adimplir suas obrigações juntamente com os respectivos credores, em procedimento que permitirá a composição dos interesses dos atores envolvidos, enfrentando de forma conjunta dos impactos decorrentes da Pandemia da COVID-19, possibilitando ao empresário o cumprimento de seu importante papel para a sociedade e para o próprio mercado.

\section{REFERÊNCIAS}

BBC. Coronavírus: o que significa a OMS declarar emergência global de saúde pública? Disponível em: <https://www.bbc.com/portuguese/internacional-51198297> Acesso em 17 jul. 2020.

BEZERRA FILHO, Manoel Justino. Nova Lei de Recuperação e Falência Comentada. $3^{\text {a }}$ ed. São Paulo: Revista dos Tribunais, 2005.

BERNARDES, Juliana Reis, SILVA, Bárbara Letícia de Sousa e LIMA, Thais Cristina Ferreira. Os impactos financeiros da Covid-19 nos negócios. Revista da FAESF, vol. 4. Número especial COVID 19. Junho (2020) 43-47 ISSN 2594 - 712543. 
BRASIL. Constituição da República Federativa do Brasil, de 5 de outubro de 1988. Disponível em: <http://www.planalto.gov.br/ccivil_03/Constituicao/Constituiçao.htm>. Acesso em: 10 jul.de 2020.

Código Civil, Lei 10.406, de 10 de janeiro de 2020. Disponível em:

<http://www.planalto.gov.br/ccivil_03/leis/2002/L10406.htm>. Acesso em: 10 jul. 2020 .

Decreto n. 10.282, de 20 de março de 2020. Define serviços públicos e atividades essenciais. Disponível em: <http://www.planalto.gov.br/ccivil_03/_ato20192022/2020/decreto/D10282.htm>. Acesso em: 31 jul. 2020.

Decreto Estadual n. 47.891, de 20 de março de 2020. Declara estado de calamidade pública no Estado de Minas Gerais. Disponível em: <https://www.legisweb.com.br/legislacao/?id=391242>. Acesso em: 30 jul. 2020.

. Decreto legislativo n. 06, de 20 de março de 2020. Reconhece, para os fins do art. 65 da Lei Complementar no 101, de 4 de maio de 2000, a ocorrência do estado de calamidade pública, nos termos da solicitação do Presidente da República encaminhada por meio da Mensagem n ${ }^{\circ}$ 93, de 18 de março de 2020. Disponível em:< http://www.planalto.gov.br/ccivil_03/portaria/DLG6-2020.htm>. Acesso em: 29 jul. 2020.

Decreto municipal n. 17.304, de 18 de março de 2020. Determina suspensão dos alvarás de funcionamento no município de Belo Horizonte. Disponível em: <http://portal6.pbh.gov.br/dom/iniciaEdicao.do?method=DetalheArtigo\&pk=12270 69>. Acesso em: 30 jul. 2020.

Lei $n^{\circ} 11.101$, de 09 de fevereiro de 2005. Regula a recuperação judicial, a extrajudicial e a falência do empresário e da sociedade empresária. Disponível em: < http://www.planalto.gov.br/ccivil_03/_ato2004-2006/2005/lei/111101.htm> Acesso em: 27 jul. 2020.

. Medida Provisória n. 927, de 22 de março de 2020. Dispõe sobre as medidas trabalhistas para enfrentamento do estado de calamidade pública reconhecido pelo Decreto Legislativo $\mathrm{n}^{\circ}$ 6, de 20 de março de 2020, e da emergência de saúde pública de importância internacional decorrente do coronavírus (covid-19), e dá outras providências. Disponível em: < http://www.planalto.gov.br/ccivil_03/_ato20192022/2020/Mpv/mpv927.htm>. Acesso em: 28 jul. 2020.

Portaria n. 188, de 3 de fevereiro de 2020. Declara Emergência em Saúde Pública de importância Nacional (ESPIN) em decorrência da Infecção Humana pelo novo Coronavírus (2019-nCoV). Disponível em: <http://www.in.gov.br/en/web/dou//portaria-n-188-de-3-de-fevereiro-de-2020-241408388> Acesso em: 12 jul. 2020.

BARACHO e CECATO, Hertha Urquiza e Maria Aurea Baroni. Da função social da empresa à responsabilidade social: reflexos na comunidade e no meio ambiente. Revista Direito e Desenvolvimento, João Pessoa, v. 7, n. 2, p. 114-128. 
FIOCRUZ. Impactos sociais, econômicos, culturais e políticos da pandemia.

Disponível em:https://portal.fiocruz.br/impactos-sociais-economicos-culturais-epoliticos-da-pandemia. Acesso em 04 jul. de 2020.

FERREIRA JÚNIOR, Reynaldo Rubem, SANTA RITA, Luciana Peixoto. Impactos da Covid-19 na Economia: limites, desafios e políticas. Cadernos de Prospecção Salvador, v. 13, n. 2, Edição Especial, p. 459-476, abril, 2020.

FILHO, Manoel Justino Bezerra. Lei de Recuperação de Empresas e Falências Comentada. $6^{\text {a }}$ edição. São Paulo: Revista dos Tribunais, 2009.

FRANCO, Vera Helena de Mello; SZTAJN, Rachel. Falência e Recuperação da Empresa em Crise. Rio de Janeiro: Elsevier, 2008.

LISBOA, Marcos de Barros et al. A racionalidade econômica da nova Lei de falências e de recuperação de empresas. In: PAIVA, Luiz Fernando Valente (coordenador). Direito Falimentar e a Nova Lei de Falências e Recuperação de Empresas. São Paulo: Quartier Latin, 2005. 